already a fair knowledge of magnetism, of heat, and of chemistry, he can very profitably begin the study of statical electricity, which can be made quickly to lead on by wellunderstood steps to the study of electric currents.

Clifton, January 22.

A. M. WORTHINGTON

\section{Glazed Frost.}

A REMARKABLy good instance of glazed frost occurred in the London suburbs on Thursday morning, January is, and evidently the same phenomenon was observed over a wide area in the south of England. A touch of real winter had spread rapidly over the country, and a strong and cold easterly wind was blowing, associated with the European anticyclone where the barometer was $3 \mathrm{I}$ inches, and with an area of low barometer readings over the Atlantic in fair proximity to our coasts. These conditions occasioned a heavy fall of snow over the northern and Midland portions of England, but there was copious rain in the south of England, with the air temperature at or slightly below the freezing point.

The trees and shrubs, as well as all ornamental work, in the garden were coated with clear ice varying in thickness from a tenth to two-tenths of an inch.

I plucked a twig with its ice coating on Streatham Hill and carried it with me to Fleet Street, where on arrival an hour later the twig remained encrusted with ice.

The shrubs and wire arches, \&c., were exceedingly beautiful, but there was no ice coating within 2 feet of the ground-my lowest screen temperature was $3 \mathrm{r}^{\circ}$.

The following description of the phenomenon is taken from "The Observer's Handbook," published by the Meteorological Office, London, rgro:-

"Glazed Frost. (German Glatteis, French Verglas.)

"A transparent smooth coating of ice covering trees, buildings, \&c. The phenomenon is usually caused by rain which freezes as it reaches the ground, and thus covers all objects with a coating of smooth transparent ice. It is very rare in our climate, but on the Continent or in America it is more common. The weight of the ice which collects is frequently sufficient to cause damage to telegraph wires, trees, \&c. It is probable that the rain in these cases consists of supercooled drops of water."

Scott's "Elementary Meteorology," p. II6, has an excellent reference to a remarkable instance of glazed frost which occurred in France on January 22-24, 1879 , taken from the Comptes rendus of the Paris Academy of Sciences.

The Isothermal Layer of the Atmosphere.

MAY I be permitted through the medium of your columns to suggest briefly what appears to me a possible explanation of the isothermal layer of the atmosphere, or stratosphere?

It is, I believe, generally admitted by astronomers that the swarm of small cosmical bodies reflecting light from the sun, known as the Zodiacal Light, extends beyond the earth's orbit, but lies outside the earth's atmosphere. My proposition is that heat received by these bodies from the sun is reflected, some of the heat reaching our atmosphere and penetrating its layers as far as the outer limits of the cloud layer. The heat thus supplied from above would be supplemented by heat received through the agency of terrestrial radiation, a larger supply being accumulated above the land than above the ocean. The greater height of the isothermal above the latter might be accounted for in this manner.

This suggestion is thrown out for the purpose of eliciting criticism, and in the hope of gaining information.

2 Amherst Road, Ealing, W., January I5. CAMPBEll HepwORTh.

\section{Concentric Joints in Ice.}

IN walking over a piece of water-logged ground, I noticed several small shallow pools which had frozen over. A number of rings, more or less parallel to the edges, were visible as in the plan. The water was found to be a NO. 2204, VOL. 88$]$ couple of inches below the top of the ice, and the rings were vertical planes, along which the ice could be readily broken. Beneatt each of these concentric "joints" the bulb formation indicated in the section (roughly to scale) was found in various stages of development, the bulbs nearest the centre being, as a rule, the most perfectly developed. The full bulb projected about three-quarters of
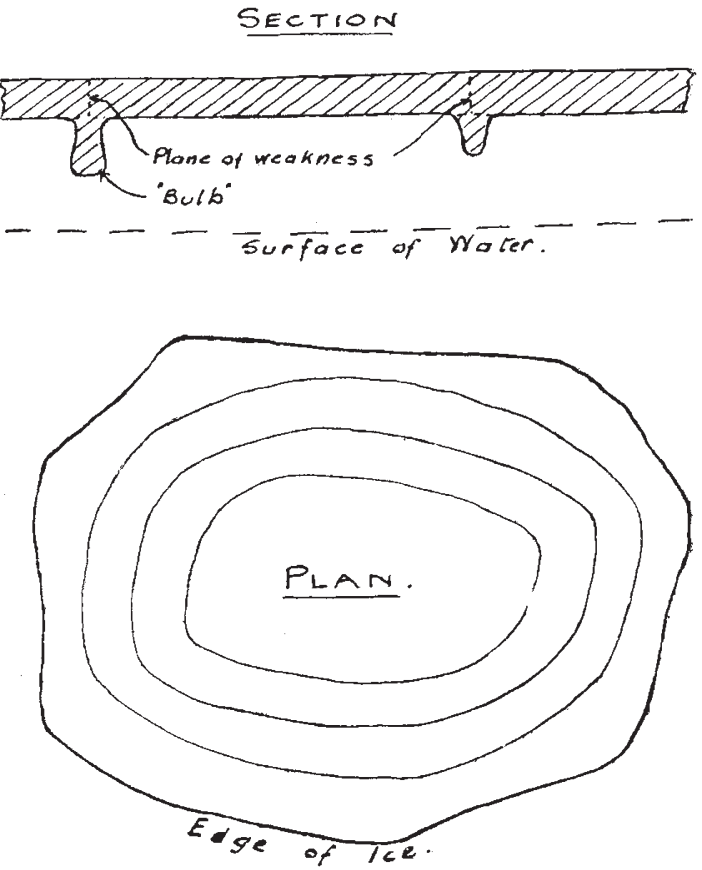

an inch below the ice-sheet, which did not vary much from five-eighths of an inch or so in thickness.

I should be interested to hear if any of your readers can explain the somewhat peculiar formation described above.

Harold J. F. Gourley.

St. Stephen's House, Victoria Embankment,

Westminster, S.W., January 15.

\section{The Late M. Radau.}

IN the obituary notice of $M$. Radau printed in the "Notes" columns of NATURE (January i1, p. 354) I notice the statement: "At no time does he seem to have held an official post as a practical astronomer." These words fail to do complete justice to this distinguished man of science. On M. Loewy's death M. Radau was appointed to succeed him as "le Membre du Bureau des Longitudes chargé de la rédaction de la Connaissance des Temps," and in this capacity he signed the "avertissements" to the volumes of the Connaissance des Temps for the years I9II, I 912 , and 1913 as the official responsible for their contents. January 20. A. M. W. Downing.

\section{The Luminosity of Cats' Eyes.}

I HAVE repeatedly observed the brilliancy of cats' eyes in the dark in particularly favourable circumstances. I have a brilliant incandescent light in my hall, and several cats on the premises. The entrance drive is in a line with the door and the hall lamp. When I call a cat in the chances are that if there she simply sits and looks at me, presenting the spectacle of two small incandescent lights glowing out of the darkness. Light, observer, and cat are all three in line, as observed by Colonel Herschel.

Southwood, Torquay, January 23
A. R. Hunt. 